\title{
Towards Mitigating the Impacts of Climate Change on Food Security: A Global Perspective
}

\section{Mansur Bello Dogondaji}

\author{
Department of Geography, \\ Shehu Shagari College of Education, Sokoto. \\ Sokoto State, Nigeria
}

\section{Doi:10.5901/ajis.2013.v2n6p167}

\begin{abstract}
Until recently, most assessment of the impact of climate change on the food and agriculture sector have focused on the implications for production and global supply of food, with less consideration of other components of the food chain. This paper takes a broader view and explores the multiple effects that global warming and climate change could have on food systems and food security. The paper also explains the concept of climate change and food security. Finally, it suggests strategies for mitigating and adopting to climate change in several key policy domain of importance for food security and the potential impacts of climate change on the four components of food security.
\end{abstract}

Keywords: Climate Change, Food Security, Adaptation, Mitigation.

\section{Introduction}

Food security is the outcome of food system processes all along the food chain. Climate change will affect food security through its impacts on all components of global, national and local food system. Climate change is real, and its first impacts are already being felt. It will first affect the people and food systems that are already vulnerable, but overtime the geographic distribution of risk and vulnerability is likely to shift. Certain livelihood groups need immediate support, but everybody is at risk. Risk exists when there is uncertainty about the future outcomes of ongoing processes or about the occurrence of future events. Adaptation is about reducing and responding to the risks climate change passes to people live and livelihood.

Mitigating climate change however, means reducing green house gas emissions and sequestering or storing carbon in the short term and of even greater importance making development choices that will reduce risk by curbing emissions over the long term. Although the entire food system is as a source of green house emissions, primary production is by far the most important component. Mean global temperatures have been increasing since about 1850, mainly owing to the accumulation of greenhouse gases in the atmosphere. The main causes are the burning of fossil fuels (coal, oil and gas) to meet increasing energy demand, and the spread of intensive agriculture to meet increasing food demand, which is often accompanied by deforestation.

The process of global warming shows no signs of abating and is expected to bring about longterm changes in weather conditions. These changes will have serious impacts on the four dimensions of food security, food availability, food accessibility, food utilization and food system stability. 


\section{Food Systems and Food Security}

The definition of food security which was adopted at the World Food Summit (WFS) in November 1996, is thus; "food security exists when all people at all times have physical or economic access to sufficient safe and nutritious food to meet their dietary needs and food preferences for an active and healthy life" (FAO, 1996). To evaluate the potential impacts of climate change on food security, the FAO stated that, "it is not enough to assess the impacts on domestic production in food insecure countries. One also needs to (i) assess climate change impacts on foreign exchange earnings, (ii) determine the availability of food-surplus countries to increase their commercial exports or food aid; and (iii) analyse how the incomes of the poor will be affected by climate change" (FAO, 2003b).

Food system on the other hand constitutes processes along a food chain which need to occur in order to bring about food security and which also determine whether or not food security is achieved. According to Global Environmental change and food systems (GEF, 2007) "Food systems encompass (i) activities related to the production, processing distribution, preparation and consumption of food; and (ii) the outcomes of these activities contributing to food security (food availability, with elements related to production, distribution and exchange; food access, with elements related to affordability, allocation and preference; and food use, with elements related to nutritional value, social value and food safety). The outcomes also contribute to environmental and other securities (e.g income). Interactions between and within biogeophysical and human environments influence both the activities and the outcomes".

Another study expresses the complexity of food systems and their link to food security as follows: "dynamic interactions between and within the biogeophysical and human environments lead to the production, processing, preparation and consumption of food, resulting in food systems that underpin food security" (Gregory, etal 2005).

The figure below shows the food system activities and food security outcomes.

Table: Food system activities and food security outcomes

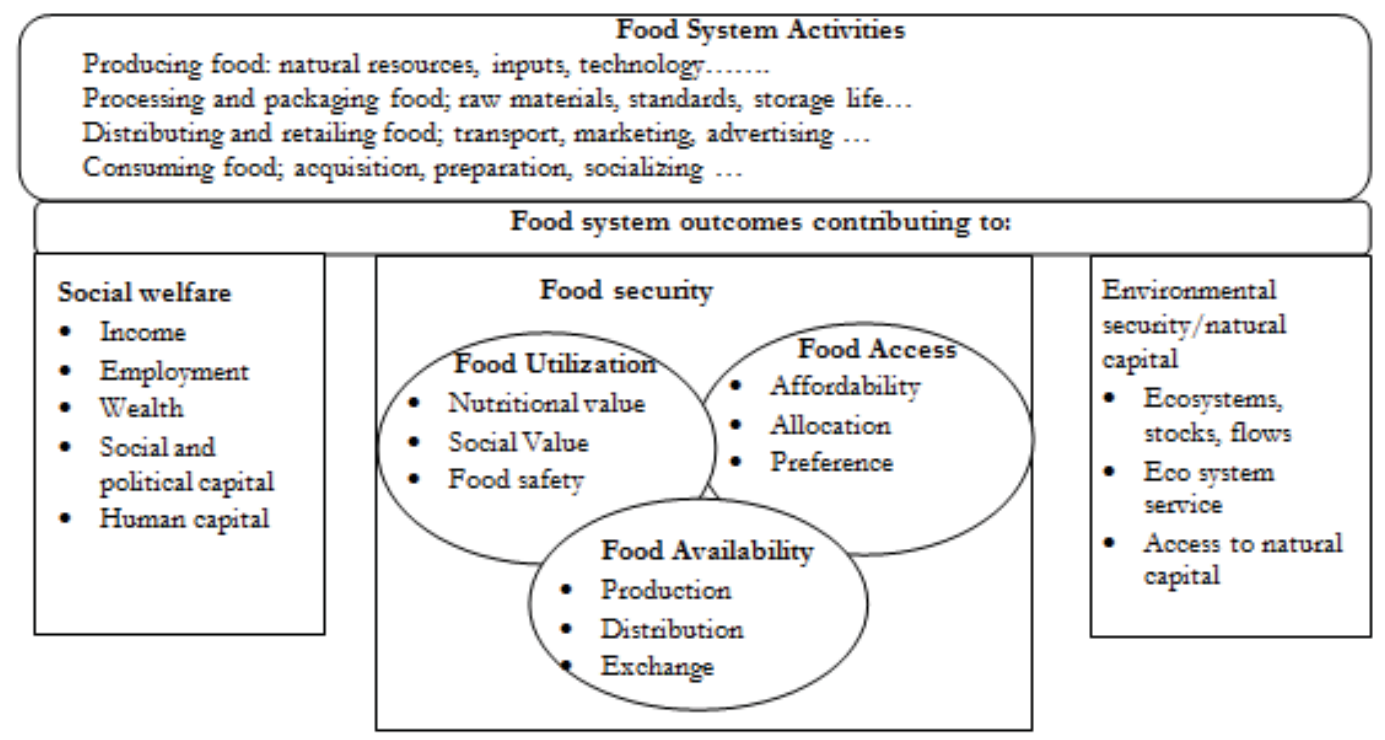

Source: GEF 2007 


\section{Climate and Climate change}

Climate refers to the characteristics conditions of the earth's lower surface atmosphere at a specific location over a long period of time. On the other hand, weather refers to the day-to-day fluctuations in these conditions at the same location. The variables that are commonly used by meteorologists to measure daily weather phenomena are air temperature, precipitation (e,g rain, sleet, snow and hail), atmospheric pressure, humidity, wind, sunshine and cloud cover.

When these weather phenomena are measured systematically at a specific location over several years, a record of observations is accumulated from which averages, ranges, percentages, maximums and minimums for each variable can be computed along with the frequency and duration of more extreme events. The World Meteorological Organization (WMO) requires the calculation of averages for consecutive periods of 30years, such a period is long enough to eliminate year-to-year variations. The averages are used in the study of climate, and as a base with which current additions can be compared (WMO, 1992).

It is important to note that there is no internationally agreed definition of the term "climate change" in the most general sense, this term encompasses all forms of climate inconstancy (i.e any differences from long term statistics of the meteorological elements calculated for different periods but relating to the same area), regardless of their statistical nature or physical causes. Climate changes may result for such factors as changes in solar emission, long - term changes in the earth's orbital elements (eccentricity, obliquity of the ecliptic, precession of the equinoxes) natural internal process of the climate system, or anthropogenic forcing (e.g increasing atmospheric concentrations of $\mathrm{CO}_{2}$ and other greenhouse gases, WMO 1992). However, the term is often used in a more restricted sense to denote a significant change (i.e a change with important economic, environmental and social effects) in the mean values of a meteorological element (particularly temperature or amount of precipitation) in the course of a certain period, where the means are taken over periods of a decade or longer (WMO, 1992, updated on June 2005). Climate change is also taken as a change in climate that is attributed, directly or indirectly, to human activity, alters the composition of the global atmosphere and is in addition to the natural climate variability observed over comparable periods (IPCC, 1995).

\section{Food Security and Climate change}

Food systems exist in the biosphere, along with all other manifestations, of human activity. Some of the significant changes in the biosphere that are expected to result from global warming will occur in the more distant future, as a consequence of changes in average weather conditions. However, the most likely scenarios of climate change indicate that increases in weather variability and the incidence of extreme weather events will be particularly significant now and in the immediate future. The projected increases in mean temperatures and precipitation will not manifest through constant gradual changes, but will instead be experienced as increased frequency, duration and intensity of hot spells and precipitation events. Whereas the annual occurrence of hot days, and maximum temperatures are expected to increase in all parts of the globe, the mean global increase in precipitation is not expected to be uniformly distributed around the world. In general, it is projected that wet regions will become wetter and dry regions drier (FAO, 2008).

Climate change variables influence biophysical factors, such as plants and animal growth, water cycle, biodiversity and nutrient recycling and the ways in which these are managed through agricultural practices and land use for food production. However, climate variables also have an impact on physical/human capital - such as roads, storage and marketing infrastructure, houses, productive assets, electricity grids and human health which indirectly changes the economic and 
socio-political factors that govern food access and utilization and can threaten the stability of food systems.

\section{Protecting food security through adaptation to climate change}

Adaptation has been defined as "adjustment in natural or human systems in response to actual or expected climatic stimuli or their effects, which moderates harm or exploits beneficial opportunities" (IPCC, 2000). It involves learning to manage new risks and strengthening resilience in the face of change. Risk management focuses on preparing to deal with shocks. Change management focuses on modifying behaviours over the medium-to-long term to avoid disruptions or declines in global and local food supplies due to changes in temperature and precipitation regimes, and to protect ecosystems through providing environmental services. The followings are the practices for adapting to climate change in the food and agriculture sector:

(1) Protecting local good supplies, assets and livelihoods against the effects of increasing weather variability and increased frequency and intensity of extreme events through:

(a) general risk management;

(b) management of risks specific to different ecosystems, marine, coastal, inland water and floodplain, forest, dry land, island, mountain, polar, cultivated;

(c) research and dissemination of crop varieties and breeds adapting to changing climatic conditions;

(d) introducing three crops to provide food, fodder and energy and enhance cash incomes.

(2) Avoiding disruptions or declines in global and local food supplies due to changes in temperature and precipitation regimes, through;

a. more efficient agricultural water management in general;

b. more efficient management of irrigation water on rice paddies;

c. improved management of cultivated land;

d. improved livestock management;

e. use of new, more energy-efficient technologies by agro-industries.

(3) Protecting ecosystems, through provision of such environmental services as;

(a) use of degraded or marginal lands for productive planted forests or other cellulose biomass for alternative fuels.

(b) Clean Development Mechanism (CDM) carbon sink tree plantings;

(c) Watershed protection

(d) Prevention of land degradations

(e) Production of coastal areas from cyclones and other coastal hazards

(f) Preservation of mangroves and their contributions to coastal fisheries

(g) Biodiversity conservation

Potential impact of climate change on the four components of food security availability, accessibility, utilization and stability.

\subsection{On Food Availability:}

food availability is determined by the physical quantities of food that are produced, stored, processed, distributed and exchanged (Devereux and Maxwell, 2001). Production of food and other agricultural commodities may keep pace with aggregate demand, but there are likely to be significant changes in local cropping patterns and farming practices. There has been a lot of research on the impacts that climate change might have on agricultural production, particularly cultivated crops. 50 percent of total crop production comes from forest and mountain ecosystems, 
including all tree crops while crop cultivated on open, arable flat land account for only 13 percent of annual global crop production. Production from both rain fed and irrigated agriculture in dry land ecosystems account for approximately 25 percent and rice produced in coastal ecosystems for about 12 percent (Millennium Ecosystems Assessment, 2005).

The impact of mean temperature increase will be experienced differently, depending on locations (Leff et al, 2004). For example, moderate warming (increases of 1 to $3^{\circ} \mathrm{C}$ in mean temperature) is expected to benefit crop and pasture yields in temperature regions, while in tropical and seasonally dry regions, it is likely to have negative impacts, particularly for cereal crops. Warming of more than $3^{0} \mathrm{C}$ is expected to have negative effects on production in all regions (IPCC, 2007). The supply of meat and other livestock products will be influenced by crop production trends, as feed crops account for roughly 25 percent of the world cropland.

For climate variables such as rainfall, soil temperature and radiation, crops have threshold beyond which growth and yield are compromised (Porter and Semenor, 2005). For examples, cereal and fruit trees yields can be damaged by a few days of temperatures above or below a certain threshold (Wheeler et al, 2000). For the 5000 plant species examined in sub-Saharan African study (Levin and Pershing, 2005), it is predicted that 81 to 97 percent of the suitable habitats will decrease in size or shift owing to climate change by 2085, between 25 and 42 percent of the species habitat are expected to be lost all together. The implications of these changes are expected to be particularly great among communities that use the plants as food or medicine.

\subsection{Food Accessibility:}

Food accessibility is a measure of the ability to secure entitlements, which are defined as the set of resources (including legal, political, economic and social) that an individual requires to obtain access to food (FAO, 2003). Food accessibility involves allocation and affordability. Food is allocated through markets and non-market distribution mechanism. There are factors that determine whether people will have access to sufficient food through market which include income generating capacity, amount of remuneration received for products and goods sold or labour and services rendered, and the ratio of the cost of a minimum daily food basket to the daily income. However, in many countries, the ratio of the cost of a minimum daily food basket to the average daily income is used as a measure of poverty (World Bank Poverty Net 2008). When this ratio fall below a certain threshold it signifies that food is affordable and people are not impoverished; when it exceeds the established threshold, food is not affordable and people are having difficulty obtaining enough to eat. This criterion is an indicator of chronic poverty and food insecurity, owing to reduced food supply and increased prices, to a sudden fall in household income or to both. Climate impacts on income earning opportunities can affect the ability to buy food, and a change in climate or climate extremes may affect the availability of certain food products, which may influence the price (Du toit and Ziervogel, 2004).

\subsection{On Food Utilization:}

This refers to the use of food and how a person is able to secure essential nutrients from the food consumed. It encompasses the nutritional value of the diet, including its composition and methods of preparation; the social values of foods which dictate what kinds of food should be served and eaten at different times of the year and on different occasion; and the quality and safety of the food supply, which can cause loss of nutrients in the food and the spread of food borne diseases if not of a sufficient standard. Food utilization however consists of nutritional value and the social and cultural values of food consumed. In the first instance, food insecurity is usually associated with malnutrition, because the diets of people who are unable to satisfy all of their food needs usually 
contain a high production of staple foods and lack the variety needed to satisfy nutritional requirements. Declines in the availability of wild foods, and limits on small-scale horticultural production due to scarcity of water or labour resulting from climate change could affect nutritional status adversely, in general, however the main impact of climate change on nutrition is likely to be felt indirectly, through its effects on income and capacity to purchase a diversity of food.

The social and cultural values of foods consumed will be affected by the availability and affordability of food. In conditions of chronic food scarcity, households ability to honour social obligations to feed guests even when they have dropped unexpectedly, is likely to breakdown and to be reinforced in locations where the impacts of climate change contribute to increasing incidence of food shortages.

\subsection{On Food System Stability:}

This is determined by the temporal availability of and access to food. In long distance food chains, storage, processing, distribution and marketing process contain in built mechanisms that have protected the global food system from instability in recent times. However, if projected increases in whether variability materialize, they are likely to lead to increases in the frequency and magnitude of food emergencies for which neither the global food system nor affected local food systems are adequately prepared. Food system stability cut across three areas: Stability of supply, stability of access and food emergencies. Many crops have annual cycles and yields fluctuate with climate variability, particularly rainfall and temperature. Maintaining the continuity of food supply when production is seasonal is therefore challenging. Droughts and floods are a particular threat to food stability and could bring about both chronic and transitory food stability. Both are expected to become more frequent, more intense and less predictable as a consequences of climate change.

\subsection{Stability of Access:}

As already noted the affordability of foods is determined by the relationship between household income and the cost of a typical food basket. Global food markets may exhibits greater price volatility, jeopardizing the stability of returns to farmers and the access purchased food of both farming and non-farming poor people.

Food Emergencies: Increasing instability of supply, attributable to the consequences of climate change, will most likely lead to increases in the frequency magnitude of food emergencies with which the global food system is ill-equipped to cope. Increasing incidence of drought may force people to migrate from one area to another, giving rise to conflict over access to resources in the receiving area. Resource scarcity can also trigger conflict and could be driven by global environmental change.

\section{Conclusion and Recommendations}

It is evidently clear from the foregoing discussion, that the potential impacts of climate change on food security are enormous and is not without great challenges both locally and internationally. To protect local food supplies, assets and livelihood from the effects of increasing whether variability and increased frequency and intensity of extreme events, adaptation measures will need to respond to a variety of risks, many of which are specific to particular ecosystems. The Millennium Ecosystems Assessment Report (2005) evaluated potential climate change impacts for ten ecosystems: urban, marine, coastal, inland water and flood plain, forest, dry land, island, mountain, polar and cultivated. The nature of the risks and the affected livelihood groups vary 
considerably from one ecosystem to another, so adaption and mitigation responses have to be tailored to local conditions and needs. In view of this, the paper recommends the followings:

a. There should be an enforcement of the Kyoto protocol which sets a legal binding commitment for 39 developed countries to reduced their Green House Gas (GHG) emissions by an average of 5.2 percent, since the targeted period to achieve these emission reductions was between 2008-2012 and up till today it has never been achieved.

b. The least developed countries (LDCS) should be assisted and have wider access to funds under the Global Environment Facility (GEF) which was established in 1991 as an independent financial organization providing grants to developing countries for projects that benefits the global environment.

c. There should be appropriate measurement and quantification of the Clean Development Mechanism (CDM) which allows developed nations to achieve part of their emission reduction obligations under the Kyoto protocol through projects in developing countries that affect greenhouse gas emission.

d. There should be portfolio investors, such as the prototype carbon fund of the World Bank and other large financial institutions, which may wish to spread their projects around the developing world, especially in poorer developing countries where the private sector would not invest.

e. There should be international development assistance to help poorer developing countries to build national capacity to develop and monitor CDM.

\section{References}

Devereux, S. and Maxwell S. eds (2001): Food Security in Sub-Saharan Africa. Brighton, U.K. Institute of Development Studies (IDS)

DU Toit, A. And Ziervogel, G, (2004). Vulnerability and Food Insecurity: Background Concepts for Informing the Development of a National FIVIMs for South Africa. Available at www.agir.agric.za/agisweb/fivimsza.

FAO. (1996). Rome Declaration and World Food Summit plan of Action. Rome. Available at www.fao.org/docrep/003/x8346e/x8346e02.htm.

FAO. (2003) Conceptual Framework for National Agricultural, Rural Development, and Food Security Strategies and Policies by K. Stamouls and A. Zezza Rome.

FAO. (2008). Expert Meeting on Global Perspectives on Fuel and food Security: Technical Report 18-20 February 2008. Rome.

Gregory, P.J ., Ingram, J.S.I. Brklacich, M. (2005). Climate Change and Food Security. Transactions of the Royal Society B; Biological Sciences 360:2139-2148.

IPCC (1995). Climate Change, a Glossary by the Intergovernmental Panel on Climate Change. Available at www.ipcc.ch/pdf/glossary/:pcc-glossary.pdf.

IPCC (2000). Special Report on Emission Sciences Scenarios Cambridge, Uk. Cambridge University Press.

IPCC (2007). Climate Change 2007, Mitigation of Climate Change. Contribution of Working Group iii to the Fourth Assessment Report of IPCC. Cambridge, Uk, Cambridge University Press.

Leff, B. Ramankutty, N. Foley J. (2004). Geographic Distribution of Major Crops across the World. Article No. GB1009 in Global Biogeochemical Cycles, 18 (1).

Levin, K. and Pershing, J. (2005). Climate Science 2005: Major New Discovering. WRI Issue Brief, Washington, Dc, WRI.

Millennium Ecosystem Assessment (2005). Ecosystems and Human Well-beings; Synthesis Washington DC, Island press for WRL.

Wheeler,T.R. Crauford, P.Q; Ellts, R.H. Porter, J.R and Vara Prasad, P.V. (2000). Temperature Variability and the Yield of Annual Crops. Agricultural Ecosystems and Environments, 82:159-167.

WMOC (1992). International Metrological Vocabulary 2nd edition Publication No. 182. Available at http://meteotem.wmo.int/meteoterm/ns?a $=\mathrm{T}=\mathrm{pl}$ start $\mathrm{u}=\propto$ direct $=y e s$ relog=yes\#expanded. 
World Bank Poverty Net. (2008). Measuring Poverty. Available at http://go.worldbank.org/vcblGGE250. 